\title{
Optimal bidding strategy for an aggregator of prosumers in energy and secondary reserve markets
}

\author{
José Iria $^{\mathrm{a}, \mathrm{b}, *}$, Filipe Soares ${ }^{\mathrm{a}}$, Manuel Matos ${ }^{\mathrm{a}, \mathrm{b}}$ \\ ${ }^{\text {a }}$ Centre for Power and Energy Systems (CPES), INESC TEC, Porto, Portugal \\ ${ }^{\mathrm{b}}$ Faculty of Engineering of University of Porto (FEUP), Porto, Portugal
}

\section{H I G H L I G H T S}

- Participation of an aggregator of prosumers in energy and secondary reserve markets.

- Two-stage stochastic optimization bidding model.

- The uncertainty of the prosumers information is modeled through a set of scenarios.

- The results suggest cost savings of $40 \%$ for both aggregator and prosumers.

\section{A R T I C L E I N F O}

\section{Keywords:}

Aggregators

Prosumers

Bidding

Electricity markets

Flexibility

\begin{abstract}
A B S T R A C T
This paper proposes a two-stage stochastic optimization model to support an aggregator of prosumers in the definition of bids for the day-ahead energy and secondary reserve markets. The aggregator optimizes the prosumers' flexibility with the objective of minimizing the net cost of buying and selling energy and secondary reserve in both day-ahead and real-time market stages. The uncertainties of the renewable generation, consumption, outdoor temperature, prosumers' preferences, and house occupancy are modeled through a set of scenarios. For a case study of 1000 prosumers, the results show that the proposed bidding strategy reduces the costs of both aggregator and prosumers by $40 \%$ compared to a bidding strategy typically used by retailers.
\end{abstract}

\section{Introduction}

\subsection{Motivation}

Several countries aim to produce most of the electricity from renewable energy sources by 2050. If this target is reached, it is expected a significant reduction of the greenhouse gas emissions. To make this transition possible, it is necessary to increase the flexibility of the energy system, so it can be used to compensate renewables variability. The recent advances of smart home technologies promise to turn passive and inflexible consumers into active and flexible prosumers. The smart home technologies include sensors, electric vehicles (EVs), smart appliances and home energy management systems (HEMSs) equipped with control, communication and monitoring functionalities [1]. These technologies can render great financial benefits to prosumers and aggregators since they enable aggregators to trade the prosumers' flexibility in the electricity markets. This paper addresses the research challenge of transforming the prosumers' flexibility into products for multiple electricity market sessions, such as energy and secondary reserve markets.

\subsection{Related work}

The aggregator is a service provider that gathers and manages groups of prosumers to trade their flexibility in the energy and reserve markets $[2,3]$. To define market products under the form of bids, the aggregator uses decision-aid optimization tools. The literature on this subject can be divided into two groups.

The first group covers bidding optimization models for the dayahead (DA) energy market. In the electric mobility context, Bessa and Matos [4,5] presented two deterministic optimization models to define demand bids for the DA energy market. The aim of both models is to minimize the cost of the aggregator buying energy in the DA market. The difference between the two optimization models is how the information of the EVs is modelled. One of the deterministic models considers the individual information of the EVs, while the second

\footnotetext{
* Corresponding author at: Centre for Power and Energy Systems (CPES), INESC TEC, Porto, Portugal.

E-mail address: jpiria@inesctec.pt (J. Iria).
} 


\section{Nomenclature}

Abbreviations and superscripts

AGC automatic generation control

AR arrival of the electric vehicle

CU curtailment

DA day-ahead

DE departure of the electric vehicle

EV electric vehicle

HEMS home energy management system

IL inflexible load

MAE mean absolute error

MIBEL Iberian electricity market

PV photovoltaic

RMSE root mean square error

RT real-time

TCL thermostatically controlled load

TSO transmission system operator

V2G vehicle-to-grid

^ point forecast

$\checkmark \quad$ EV charging

$\wedge \quad$ EV discharging

$+\quad$ positive imbalance

- negative imbalance or band not supplied

Indices and sets

$j \in J \quad$ scenarios

$t \in T \quad$ time intervals

$v \quad$ type of load/generator $\{E V, T C L, I L, P V\}$

$i \in I^{v} \quad$ load/generator

$T^{v} \subset T \quad$ sub-sets of time intervals

\section{$O \subset T$ house occupancy}

Parameters

$\begin{array}{ll}C O P & \text { thermal capacitance }\left(\mathrm{kWh} /{ }^{\circ} \mathrm{C}\right) \\ \bar{P} & \text { coefficient of performance } \\ P r & \text { maximum electric power }(\mathrm{kWh}) \\ \overline{S O C} & \text { maximum state-of-charge }(\mathrm{kWh}) \\ \underline{S O C} & \text { minimum state-of-charge }(\mathrm{kWh}) \\ R & \text { thermal resistance }\left({ }^{\circ} \mathrm{C} / \mathrm{kW}\right) \\ \vartheta & \text { heat gains and losses not modeled explicitly }\left({ }^{\circ} \mathrm{C}\right) \\ \lambda & \text { price }(€ / \mathrm{kWh} \text { or } € / \mathrm{kW}) \\ \pi & \text { probability of occurrence of the scenarios } \\ \eta & \text { charging and discharging efficiency } \\ \Delta t & \text { duration of time interval } t(1 \mathrm{~h}) \\ \bar{\theta} & \text { maximum temperature of comfort }\left({ }^{\circ} \mathrm{C}\right) \\ \hat{\theta} & \text { minimum temperature of comfort }\left({ }^{\circ} \mathrm{C}\right) \\ \theta^{o} & \text { outdoor temperature }\left({ }^{\circ} \mathrm{C}\right) \\ \varnothing & \text { ratio of utilization to band }\end{array}$

Variables

$B \quad$ band $=D+U(\mathrm{~kW})$

$D \quad$ downward band $(\mathrm{kW})$

$U \quad$ upward band (kW)

$\Delta D \quad$ downward band not supplied (kW)

$\Delta U \quad$ upward band not supplied (kW)

$E \quad$ energy (kWh)

$\Delta E \quad$ energy imbalance (kWh)

$P \quad$ electric power $(\mathrm{kW})$

SOC state-of-charge (kWh)

$\theta$ temperature $\left({ }^{\circ} \mathrm{C}\right)$ considers the aggregated information. The optimization models $[3,4]$ do not consider the stochastic behavior of the EVs in the definition of the energy bids, which increases the possibility of the aggregator incurring into real-time (RT) energy imbalances. Vagropoulos and Bakirtzis [6] proposed a scenario-based two-stage stochastic optimization to model the uncertainty of the EV driving patterns. Instead of scenarios, Baringo and Amaro [7] considered confidence bounds to model the uncertainty of the mobility patterns. Confidence bounds reduce the computational complexity of scenario-based stochastic programming. Under the assumption of direct control over thermostatically controlled loads (TCLs), the references $[8,9]$ present two deterministic optimization models to define demand bids for the DA energy market. The first model [8] optimizes the operation of residential TCLs, while the second [9] is focused on the optimization of space heating systems on both residential and commercial sectors.

Iria and Soares $[3,10]$ extended the range of the aggregator to the supply side of the DA energy market by adding renewable generators to the aggregator's portfolio. These two approaches $[3,10]$ assume that the aggregator does not have enough market power to affect the wholesale prices, i.e. they consider that the aggregator is a price-taker. An alternative approach was exploited by references $[11,12]$. They assumed that the aggregator is a price-maker and can affect the energy prices if its size reaches a market share of $10-15 \%$. In the scope of local energy markets, the works $[13,14]$ proposed peer-to-peer approaches to enable energy trading between prosumers. Such approaches have the advantage of not depending on third parties. Nonetheless, they present the disadvantage of not enabling the participation of prosumers in reserve services.

The second group covers bidding optimization models for the DA energy and reserve markets. Bessa and Matos [15] formulated a deterministic optimization model to support the participation of an EV aggregator in the DA energy and secondary reserve markets. The aggregator defines demand and band bids based on the forecasted flexibility of an EV fleet. The aim is to minimize the net cost of the aggregator buying energy and selling secondary reserve. Secondary reserve is typically known as spinning or regulation reserve in the U.S. markets $[16,17]$. Vagropoulos and Bakirtzis [6] incorporated the uncertainty of the EV charging requirements in the stochastic optimization of demand and band bids for the DA energy and regulation reserve markets. These two works $[6,15]$ only consider the flexibility of the EVs to shift consumption, i.e. they do not consider vehicle-to-grid (V2G) a viable solution to provide regulation services, as works $[18,19]$.

Ref. [20] proposed a robust optimization to define band bids for the DA secondary reserve market. The aggregator exploits the flexibility of HVACs to minimize the net cost of buying electricity in the retailing market and selling band in the secondary reserve market. The authors incorporated the uncertainty of reserve activation through polyhedral set constraints. In a later work, Vrettos and Anderson [21] proposed a hybrid robust and stochastic optimization to define band bids for the DA secondary reserve market. The authors added to the objective function of [20] a stochastic term to value the expected revenue of reserve activation. The results showed that hybrid robust and stochastic formulation increases the band capacity up to $5 \%$ compared to the robust formulation.

One of the important points highlighted by references [18-21] is that TCLs and EVs are technically capable of supplying secondary reserve. The studies [22-24] experimentally demonstrated that EVs, TCLs, and PVs can effectively follow set-points communicated by an 
aggregator or an automatic generation control (AGC) system in the laboratory facilities of INESC TEC [24] and Berkeley Lab [22,23].

\subsection{Contributions}

This paper proposes a novel two-stage stochastic optimization model to support an aggregator of prosumers in the definition of bids for the DA energy and secondary reserve markets. The aim is to minimize the net cost of the aggregator trading energy and secondary reserve in both DA and RT market stages. The bids result from the joint optimization of flexible and inflexible consumption and generation. The flexible generation includes photovoltaic (PV) units and EVs while the flexible load includes TCLs and EVs. The inflexible consumption results from the operation of non-controlled appliances. The uncertainties of PV generation, consumption, outdoor temperature, prosumers' preferences, and house occupancy are incorporated in the optimization problem through a set of scenarios.

The proposed bidding optimization model goes beyond the state-ofthe-art methodologies [2-21]. First, it considers different sources of uncertainty and flexibility in the joint optimization of energy and secondary reserve bids, which increases the reliability and economic value of the bids compared to deterministic approaches $[8,9]$ and single resource optimization approaches [4-8]. Second, it extends the bidding range of the aggregator to the supply and demand sides of the energy market, as well as to the secondary reserve market, empowering the aggregator with multiple bidding options compared to single bidding strategies [20-23]. Third, it considers the economic implications of trading energy and reserves in both DA and RT market stages, contrarily to single-stage optimization approaches [8-12] only focused on the DA market. Fourth, it values the prosumers' flexibility by transforming it into energy and reserve services with high economic value. Fifth, it avoids prosumers from investing in dedicated storage technologies to store excess of renewable generation, since the excess is transformed into market products. Sixth, it contributes to reducing the carbon footprint of the generation system by reducing the use of environmentally unfriendly fuel generators in reserve services. Finally, it allows identifying the prosumers' characteristics that maximize the aggregator's profit. A case study of 1000 prosumers from the Iberian market is used to demonstrate the claimed innovation aspects.

\subsection{Paper organization}

The remaining paper is organized as follows. Section 2 describes the participation of the aggregator in DA energy and secondary reserve markets. Section 3 presents the bidding optimization model. Sections 4 and 5 describe the case study and results. The conclusions are presented in Section 6.

\section{Participation of the aggregator in the day-ahead energy and secondary reserve markets}

\subsection{Description of the electricity market framework}

The participation of the aggregator in the electricity market follows the rules of the Iberian market (MIBEL) $[25,26]$. MIBEL is a typical European market based on sequential trading, such as Nord Pool and EPEX. In a sequential market, energy is traded first and reserves are contracted afterward. Contrarily to European markets, U.S. markets are typically joint markets where energy and reserves are co-optimized (e.g., CAISO and ERCOT). The proposed bidding optimization model can easily be adapted and applied to any joint and sequential market, since the aggregator co-optimizes bids before both energy and reserve market sessions, as described in Fig. 1.

\subsubsection{Energy market}

The MIBEL covers the Portuguese and Spanish control areas. The DA

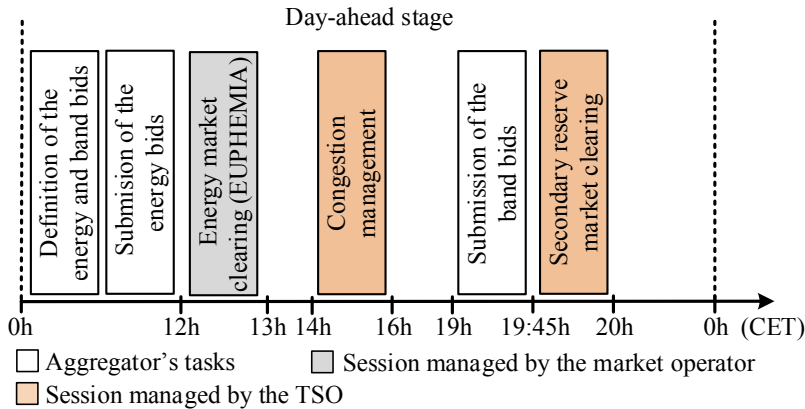

Fig. 1. Aggregator's tasks and electricity market sessions.

energy market is a double-sided auction, where market agents submit energy hourly bids for the $24 \mathrm{~h}$ of the next day. Market participants submit energy bids to the power exchange until the 12th hour. The energy bids of MIBEL and other European markets are collected and submitted to the EUPHEMIA platform (European market solver [27]). The EUPHEMIA clears the offers (MWh) and prices ( $€ / M W h)$ such that the social welfare is maximal and the power flows between the European bidding areas are not exceeded. The clearing prices are published at the 13th hour. Afterward, the physical bilateral contracts are added to the clearing offers of the DA energy market. Before the 16th hour, the transmission system operator (TSO) performs congestion management to generate viable energy schedules. Market-based or technical-based mechanisms can be activated, if network problems are detected. Fig. 1 describes the timeline of the DA energy market.

Days after the delivery, the market operator settles the energy transitions. The aggregator pays the energy bought and charges the energy sold in the DA energy market. The energy deviations are settled at imbalance prices. Portugal and Spain use the two-price system to value energy imbalances. The positive and negative imbalance prices of Portugal result from a complex function of energy and reserve prices, as described in [28].

\subsubsection{Secondary reserve market}

The secondary reserve (or regulation reserve in the U.S. markets) consists of loads and generators under the direct control of the TSO, via an AGC, for increasing or decreasing generation or consumption. The response time is very fast (e.g., $<5 \mathrm{~s}$ ) and is used to restore the frequency to its nominal value and to maintain the desired exchanges between neighboring control areas. The secondary reserve is remunerated under two concepts: band availability and utilization (in both directions). The band availability is traded under the form of bids (MW), which are selected by an economic merit order and remunerated by a common marginal price $(€ / \mathrm{MW})$. In Portugal, the band bids are divided $2 / 3$ for upward direction and $1 / 3$ for downward direction.

The submission period of the band bids to the DA secondary reserve market is between the 19:00 and 19:45 $\mathrm{h}$ of the prior day before delivery. The market clearing is followed by the submission period, as described in Fig. 1. The TSO is responsible for acquiring secondary reserve and managing the market clearing. During the operating day, the AGC dispatches the band. The band utilization (MW) is valued at the marginal price $(€ / \mathrm{MWh})$ of the tertiary reserve market of MIBEL. In the settlement phase, the TSO pays the reserve bought and charges the reserve not supplied. The penalty for the reserve not supplied is proportional to the band price [26].

\subsection{Sequential tasks of the aggregator in the day-ahead market}

The aggregator may participate in multiple DA market sessions, as shown in Fig. 2. It may choose to participate only in the energy market or in both energy and secondary reserve markets. As price-taker, the aggregator submits non-priced energy and band bids to the DA markets. This means that demand bids are submitted at market cap price, 


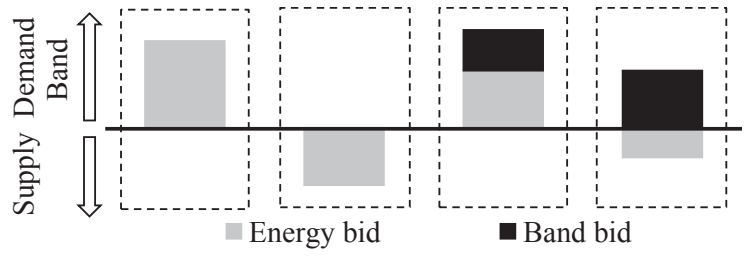

Fig. 2. Four bidding options.

whereas supply and secondary band bids are presented at zero price.

The participation of the aggregator in the DA energy and secondary reserve markets requires the submission of energy and band bids to two different market sessions. The aggregator co-optimizes energy and band bids. Before the 12th hour, the aggregator submits energy bids. The band bids are submitted between the 19:00 and 19:45 h. Fig. 1 shows the timeline of the aggregator's tasks.

\subsection{Information chain in the day-ahead stage}

Fig. 3 describes the flow of information between the aggregator, prosumers, TSO, and electricity market during the day-ahead stage. Nine day-ahead actions are identified, as follows:

1. communication of the prosumers information. The prosumers information includes state-of-operation and parameters of the appliances, preferences of the prosumers, end-user engagement information, consumption, generation, etc.;

2. definition of the energy and band bids for the DA energy and secondary reserve markets. The aggregator defines the bids through the bidding optimization model described in Section 3;

3. submission of the energy bids (MWh and $€ / M W h$ );

4. energy market clearing performed by the EUPHEMIA platform. The market operator participates in this process;

5. congestion management executed by the TSO. The exchange of data includes cleared energy bids (from the EUPHEMIA platform) and viable energy schedules (from the TSO);

6. communication of the viable energy schedules (MWh) and clearing prices $(€ / \mathrm{MWh})$;

7. submission of the band bids ( $M W$ and $€ / M W$ );

8. secondary reserve market clearing. The TSO buys band availability;

9. communication of the clearing band offers (MW) and prices $(€ / \mathrm{MW})$

\subsection{Interface between the aggregator and prosumer}

The aggregator interfaces with the prosumer through a HEMS installed by it. In the DA stage, the HEMS gathers and communicates prosumers information, as described in Fig. 4. In this framework, the HEMS has the following functionalities: metering the consumption and generation of appliances; monitoring and acquiring the state-of-operation of appliances; enabling the exchange of information between the prosumer and aggregator (e.g., preferences); engaging and advising the prosumers into cost-efficiency behaviors and services; and controlling

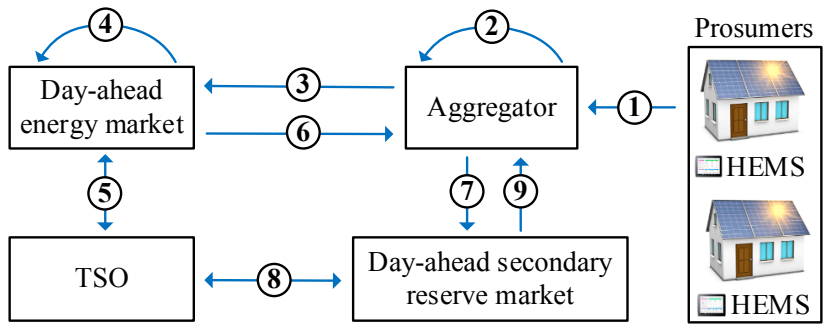

Fig. 3. Flow of information between the aggregator, prosumers, TSO, and electricity market during the day-ahead stage.

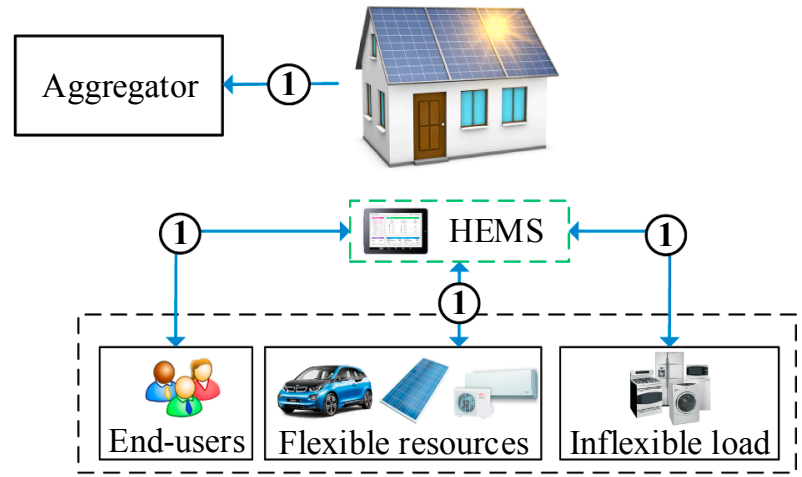

Fig. 4. Interface between the aggregator and prosumer.

flexible resources according to set-points communicated by the aggregator during the RT phase. The prosumer can interact with the HEMS through a smartphone application.

This paper considers three sources of flexibility: TCLs, EVs, and PVs. The EVs are sources of demand and generation flexibility (V2G), while the TCLs are only sources of demand flexibility and the PV units are only sources of generation flexibility. Being a source of demand flexibility means that the resource is capable of increasing, decreasing or shifting consumption. On the other hand, a source of generation flexibility is capable of increasing and decreasing generation. The flexibility depends on the technical characteristics of the appliances and the preferences of the prosumers described in Table 1. The preferences set the flexibility range that does not compromise the comfort levels of the prosumers. For instance, the thermal comfort of a prosumer is defined by a range of temperatures (e.g., $[20-22]{ }^{\circ} \mathrm{C}$ ) predefined by him.

This paper is focused on the definition of bids for the DA energy and secondary reserve markets leaving the RT operation for future work. Examples of RT control strategies can be found in [29,30].

\section{Day-ahead bidding optimization model}

The energy $E_{t}^{D A}$ and band bids $B_{t}^{D A}$ are defined by a two-stage stochastic optimization model. The main characteristics of the optimization model are described below:

1. two-stage: the optimization model defines energy and band bids for the DA markets, taking into account multiple possible RT outcomes of flexibility, generation, and consumption. The DA market is the first-stage and the RT phase is the second-stage;

2. stochastic: the uncertainties of the prosumers are incorporated in the optimization model through a set of scenarios. The scenarios model possible RT outcomes of PV generation, consumption, outdoor temperature, prosumers' preferences, and house occupancy.

\subsection{Objective function}

The two-stage stochastic optimization model (1)-(27) is formulated as a minimization problem. The aim is to minimize the net cost of the

Table 1

Main characteristics of the flexible resources.

\begin{tabular}{lll}
\hline Resource & Physical and technical characteristics & Prosumer's preferences \\
\hline EV & $\begin{array}{l}\text { Battery capacity } \\
\text { Maximum and minimum SOC }\end{array}$ & $\begin{array}{l}\text { Plug-in period } \\
\text { SOC at departure time }\end{array}$ \\
& $\begin{array}{l}\text { Charging and discharging power values } \\
\text { Charging and discharging efficiencies }\end{array}$ & \\
TCL & Thermal capacity and resistance & Range of thermal comfort \\
& Thermal power & House occupancy \\
PV & Available solar energy & - \\
\hline
\end{tabular}


aggregator trading energy and secondary reserve in both DA and RT market stages. The objective function (1) has five terms:

1. the first term $\hat{\lambda}_{t}^{E} E_{t}^{D A}$ is the net cost of buying and selling energy $E_{t}^{D A}(\mathrm{kWh})$ in the DA energy market. Negative values of $E_{t}^{D A}$ are supply bids and positive values are demand bids. $\hat{\lambda}_{t}^{E}(€ / \mathrm{kWh})$ is the energy price;

2. the second term $-\left(\hat{\lambda}_{t}^{B} D_{j, t}^{D A}+\hat{\lambda}_{t}^{B} U_{j, t}^{D A}\right) \Delta t$ is the revenue of selling band in the DA secondary reserve market. The band is divided into upward $U_{t}^{D A}$ and downward $D_{t}^{D A}$ directions $B_{t}^{D A}=D_{t}^{D A}+U_{t}^{D A}(k W)$. $\hat{\lambda}_{t}^{B}(€ / \mathrm{kW})$ is the band price;

3. the third term $\hat{\lambda}_{t}^{E,-} \Delta E_{j, t}^{-}-\hat{\lambda}_{t}^{E,+} \Delta E_{j, t}^{+}$is the expected imbalance cost. It values deviations between DA energy commitments and RT energy realizations. A positive imbalance $\Delta E_{j, t}^{+}(\mathrm{kWh})$ is a shortage of demand or a surplus of generation. A negative imbalance $\Delta E_{j, t}^{-}$is a surplus of demand or a shortage of generation. Energy imbalances are valued at $\hat{\lambda}_{t}^{E,+}(€ / \mathrm{kWh})$ and $\hat{\lambda}_{t}^{E,-}$;

4. the fourth term $\hat{\lambda}_{t}^{D} \widehat{\varnothing}_{t}^{D} D_{j, t}^{R T}-\hat{\lambda}_{t}^{U} \widehat{\varnothing}_{t}^{U} U_{j, t}^{R T}$ is the expected revenue of mobilizing upward $\widehat{\varnothing}^{U} U_{j, t}^{R T}(\mathrm{~kW})$ and downward $\widehat{\varnothing}^{D} D_{j, t}^{R T}$ bands during RT. In the MIBEL, mobilizing downward band represents a cost for the aggregator. The mobilized upward band is valued at upward tertiary reserve price $\hat{\lambda}_{t}^{U}(€ / \mathrm{kWh})$ and the mobilized downward band is valued at downward tertiary reserve price $\hat{\lambda}_{t}^{D}$. The parameter $\widehat{\varnothing}_{t}^{U}$ is the ratio of upward utilization to band and $\widehat{\varnothing}_{t}^{D}$ is the ratio of downward utilization to band. The variable $U_{j, t}^{R T}$ is the upward band and $D_{j, t}^{R T}$ is the downward band;

5. the fifth term $\hat{\lambda}_{t}^{B,-} \Delta U_{j, t}+\hat{\lambda}_{t}^{B,-} \Delta D_{j, t}$ is the expected penalty for band not supplied. It values the deviations between band bids $D_{t}^{D A}+U_{t}^{D A}$ and RT bands $D_{t}^{R T}+U_{t}^{R T}$. The downward $\Delta D_{j, t}(\mathrm{~kW})$ and upward $\Delta U_{j, t}$ bands not supplied are valued at penalty price $\hat{\lambda}_{t}^{B,-}(€ / \mathrm{kW})$.

The energy and band bids are first-stage variables and are independent of the realization of any specific scenario $j \in J$. The RT variables are second-stage variables and are dependent on the realization of scenarios. The probability of occurrence of each scenario $j$ is defined by $\pi_{j}$. The optimization horizon is define by a set of time intervals $t \in T$ of duration $1 \mathrm{~h} \Delta t(h)$.

$$
\begin{aligned}
& \operatorname{Min} \sum_{t \in T}\left[\hat{\lambda}_{t}^{E} E_{t}^{D A}-\left(\hat{\lambda}_{t}^{B} D_{j, t}^{D A}+\hat{\lambda}_{t}^{B} U_{j, t}^{D A}\right) \Delta t\right. \\
& +\sum_{j \in J} \pi_{j}\left(\hat{\lambda}_{t}^{E,-} \Delta E_{j, t}^{-}-\hat{\lambda}_{t}^{E,+} \Delta E_{j, t}^{+}+\left(\hat{\lambda}_{t}^{D} \widehat{\varnothing}_{t}^{D} D_{j, t}^{R T}-\hat{\lambda}_{t}^{U} \widehat{\varnothing}_{t}^{U} U_{j, t}^{R T}\right.\right. \\
& \left.\left.\left.+\hat{\lambda}_{t}^{B,-} \Delta U_{j, t}+\hat{\lambda}_{t}^{B,-} \Delta D_{j, t}\right) \Delta t\right)\right]
\end{aligned}
$$

\subsection{Market trading and energy balance constraints}

Constraint (2) defines the energy balance between RT and DA market stages. Constraints (3) and (4) define the downward and upward bands not supplied. Constraints (5) and (6) divide the band into upward and downward directions. MIBEL splits the band into $2 / 3$ for upward and $1 / 3$ for downward [15]. The value of $\tau$ is 2 for the MIBEL.

$$
\begin{aligned}
& \Delta E_{j, t}^{-}-\Delta E_{j, t}^{+}+\left(D_{j, t}^{R T}-U_{j, t}^{R T}\right) \Delta t=E_{j, t}^{R T}-E_{t}^{D A}, \quad \forall j \in J, t \in T \\
& \Delta D_{j, t}=D_{t}^{D A}-D_{j, t}^{R T}, \quad \forall j \in J, t \in T \\
& \Delta U_{j, t}=U_{t}^{D A}-U_{j, t}^{R T}, \quad \forall j \in J, t \in T \\
& U_{j, t}^{R T}=\tau D_{j, t}^{R T}, \quad \forall j \in J, t \in T \\
& U_{t}^{D A}=\tau D_{t}^{D A}, \quad \forall t \in T
\end{aligned}
$$

$$
\Delta D_{j, t}, \Delta U_{j, t}, \Delta E_{j, t}^{-}, \Delta E_{j, t}^{+}, D_{j, t}^{R T}, U_{j, t}^{R T} \geq 0, \quad \forall j \in J, t \in T
$$

Constraint (8) sets the expected net load $E_{j, t}^{R T}$ in RT. The electric power $P_{j, i, t}^{v}$ of the appliance $i \in I^{v}$ is positive for load and negative for generation.

$E_{j, t}^{R T}=\sum_{v \in\{E V, T C L, I L, P V\}}\left(\sum_{i \in I^{v}} P_{j, i, t}^{v} \Delta t\right), \quad \forall j \in J, t \in T$

Constraints (9) and (10) set the upward and downward bands provided by the EVs, TCLs, and PVs in RT. The upward band defines the flexibility of the appliances to increase generation or decrease consumption in RT. The downward band defines the flexibility of the appliances to decrease generation or increase consumption in RT.

$U_{j, t}^{R T}=\sum_{v \in\{E V, T C L, P V\}}\left(\sum_{i \in I^{v}} U_{j, i, t}^{v}\right), \quad \forall j \in J, t \in T$

$D_{j, t}^{R T}=\sum_{v \in\{E V, T C L, P V\}}\left(\sum_{i \in I^{v}} D_{j, i, t}^{v}\right), \quad \forall j \in J, t \in T$

\subsection{Electric vehicle constraints}

The optimization of the EV requires thirteen constraints. Constraints (11) and (12) set the ranges of charging power $P_{j, i, t}^{\vee}(\mathrm{kW})$ and discharging power $P_{j, i, t}^{\wedge}$. This formulation does not require the adoption of binary variables to avoid simultaneous charging and discharging due to the price structure of the objective function. The net power of the $\mathrm{EV}$ is given by $P_{j, i, t}^{E V}=P_{j, i, t}^{\vee}-P_{j, i, t}^{\wedge}$. Constraints (13) and (14) set the SOC $(\mathrm{kWh})$ within its limits $\left[\mathrm{SOC}_{i}, \overline{S O C}_{i}\right]$. Constraint (15) ensures that the SOC at departure time $t_{j, i}^{D E}$ is satisfied. The goal is to ensure the preferences $t_{j, i}^{D E}$ and $S O C_{j, i}^{D E}$ of the EV driver.

$0 \leq P_{j, i, t}^{\wedge} \leq \bar{P}_{i}^{E V}, \quad \forall j \in J, i \in I^{E V}, t \in T_{j, i}^{E V}$

$0 \leq P_{j, i, t}^{\vee} \leq \bar{P}_{i}^{E V}, \quad \forall j \in J, i \in I^{E V}, t \in T_{j, i}^{E V}$

$\operatorname{SOC}_{j, i, t+1}=S O C_{j, i, t}+\left(\eta_{i} P_{j, i, t}^{\vee}-P_{j, i, t}^{\wedge} / \eta_{i}\right) \cdot \Delta t, \quad \forall j \in J, i \in I^{E V}, t \in T_{j, i}^{E V}$

$\underline{S O C}_{i} \leq S O C_{j, i, t+1} \leq \overline{S O C}_{i}, \quad \forall j \in J, i \in I^{E V}, t \in T_{j, i}^{E V}$

$S O C_{j, i, t, i, i}^{D E} \geq S O C_{j, i}^{D E}, \quad \forall j \in J, i \in I^{E V}$

The band supplied by the EV is defined by constraints (16)-(23). The V2G enables the provision of downward band by increasing consumption or decreasing generation in RT, and upward band by decreasing consumption or increasing generation in RT. Constraint (16) limits the downward band $D_{j, i, t}^{E V}$ to the available discharging power. Constraint (17) limits the upward band $D_{j, i, t}^{E V}(k W)$ to the available discharging power. Constraints (18)-(21) ensure that the EV only provides upward and downward bands if the SOC is within the limits ]$\underline{S O C}_{i}, \overline{S O C}_{i}$.

$$
\begin{aligned}
& 0 \leq D_{j, i, t}^{E V} \leq \bar{P}_{i}^{E V}-P_{j, i, t}^{\wedge}, \quad \forall j \in J, i \in I^{E V}, t \in T_{j, i}^{E V} \\
& 0 \leq U_{j, i, t}^{E V} \leq \bar{P}_{i}^{E V}-P_{j, i, t}^{\vee}, \quad \forall j \in J, i \in I^{E V}, t \in T_{j, i}^{E V} \\
& U_{j, i, t}^{E V} \leq \frac{\overline{S O C}_{i}-S O C_{j, i, t+1}}{\Delta t \cdot \eta_{i}}, \quad \forall j \in J, i \in I^{E V}, t \in T_{j, i}^{E V} \\
& U_{j, i, t}^{E V} \leq \frac{\left(S O C_{j, i, t+1}-\underline{S O C}_{i}\right) \eta_{i}}{\Delta t}, \quad \forall j \in J, i \in I^{E V}, t \in T_{j, i}^{E V} \\
& D_{j, i, t}^{E V} \leq \frac{\overline{S O C}_{i}-S O C_{j, i, t+1}}{\Delta t \cdot \eta_{i}}, \quad \forall j \in J, i \in I^{E V}, t \in T_{j, i}^{E V}
\end{aligned}
$$


$D_{j, i, t}^{E V} \leq \frac{\left(S O C_{j, i, t+1}-\underline{S O C}_{i}\right) \eta_{i}}{\Delta t}, \quad \forall j \in J, i \in I^{E V}, t \in T_{j, i}^{E V}$

Constraints (22) and (23) limit the band in both directions to the energy required by the prosumer to charge the $\mathrm{EV}\left(S O C_{j, i}^{D E}-S O C_{j, i}^{A R}\right)$.

$\sum_{t \in T_{j, i}^{E V}} D_{j, i, t}^{E V} \cdot \Delta t \cdot \eta_{i} \leq S O C_{j, i}^{D E}-S O C_{j, i}^{A R}, \quad \forall j \in J, i \in L^{E V}$

$\sum_{t \in T_{j, i}^{E V}} U_{j, i, t}^{E V} \cdot \Delta t \cdot \eta_{i} \leq S O C_{j, i}^{D E}-S O C_{j, i}^{A R}, \quad \forall j \in J, i \in L^{E V}$

The EV parameters can be fixed or variable. The variable parameters assume the form of scenarios $\left\{t_{j, i}^{D E}, t_{j, i}^{A R}, S O C_{j, i}^{D E}, S O C_{j, i}^{A R}, T_{j, i}^{E V}, \forall j, i\right\}$, and are computed on a daily basis by the aggregator based on the information communicated by the HEMS. The aggregator uses a seasonal naive forecasting algorithm to generate the scenarios [2,3]. The fixed and variable parameters are described in Tables 2 and 3.

\subsection{Photovoltaic generation constraints}

The optimization of the PV generation requires four constraints. Constraint (24) sets the power generation $P_{j, i, t}^{P V}(\mathrm{~kW})$. Constraint (25) ensures the limits of the curtailment of PV generation $P_{j, i, t}^{C U}(\mathrm{~kW})$. Constraints (26) and (27) set the range of downward $D_{j, i, t}^{P V}$ and upward $U_{j, i, t}^{P V}(\mathrm{~kW})$ bands. The uncertainty of the PV generation is modeled through a set of scenarios $\left\{\operatorname{Pr}_{j, i}^{P V}, \forall j, i\right\}$.

$P_{j, i, t}^{P V}=P_{j, i, t}^{C U}-P_{j, i, t}^{P V}, \quad \forall j \in J, i \in I^{P V}, t \in T$

$0 \leq P_{j, i, t}^{C U} \leq \operatorname{Pr}_{j, i, t}^{P V}, \quad \forall j \in J, i \in I^{P V}, t \in T$

$0 \leq D_{j, i, t}^{P V} \leq P_{j, i, t}^{C U}, \quad \forall j \in J, i \in I^{P V}, t \in T$

$0 \leq U_{j, i, t}^{P V} \leq \operatorname{Pr}_{j, i, t}^{P V}-P_{j, i, t}^{C U}, \quad \forall j \in J, i \in I^{P V}, t \in T$

\subsection{Thermostatically controlled load constraints}

The TCL consists of a heat pump with heating capabilities. The optimization of the TCL requires six constraints. Constraints (28) and (29) set the ranges of electric power $P_{j, i, t}^{T C L}(\mathrm{~kW})$, upward band $U_{j, i, t}^{T C L}(\mathrm{~kW})$ and downward band $D_{j, i, t}^{T C L}$. Constraints (30) and (31) define temporal trajectories of room temperatures $\theta_{j, i, t+1}^{D}$ and $\theta_{j, i, t+1}^{U}\left({ }^{\circ} \mathrm{C}\right)$ for the extreme points of the band domain $P_{j, i, t}^{T C L}-D_{j, i, t}^{T C L}$ and $P_{j, i, t}^{T C L}+U_{j, i, t}^{T C L}$. Constraints (32) and (33) guarantee that the temporal trajectories (30) and (31) satisfy the thermal comfort of the prosumer $\left[\underline{\theta}_{i}, \bar{\theta}_{i}\right]$ in the periods of house occupancy. In short, the four constraints (30)-(33) ensure that the preferences of the prosumer are satisfied for any value of band within the flexibility domain of the TCL.

$0 \leq P_{j, i, t}^{T C L}+U_{j, i, t}^{T C L} \leq \bar{P}_{i}^{T C L}, \quad \forall j \in J, i \in I^{T C L}, t \in T$

$P_{j, i, t}^{T C L} \geq D_{j, i, t}^{T C L}, \quad \forall j \in J, i \in I^{T C L}, t \in T$

$\theta_{j, i, t+1}^{D}=\beta_{i} \theta_{j, i, t}^{D}+\left(1-\beta_{i}\right)\left(\theta_{j, t}^{o}+\operatorname{COP}_{i} \cdot R_{i} \cdot\left(P_{j, i, t}^{T C L}-D_{j, i, t}^{T C L}\right)\right)$

$$
+\vartheta_{j, i, t}, \quad \forall j \in J, i \in I^{T C L}, t \in T
$$

Table 3

Variable parameters and sets of the electric vehicle.

\begin{tabular}{|c|c|c|c|}
\hline Symbol & Unit & Name & Description \\
\hline$t^{D E}$ & - & Departure time & $t^{D E}$ is set by the prosumer \\
\hline$t^{A R}$ & - & Arrival time & - \\
\hline$T^{E V}$ & - & $\begin{array}{l}\text { Availability } \\
\text { period }\end{array}$ & $\begin{array}{l}\text { The availability is defined by the period } \\
\text { between the arrival and departure } \\
\text { times }\left[t^{A R}, \ldots, t^{D E}\right]\end{array}$ \\
\hline$S O C^{A R}$ & $\mathrm{kWh}$ & $\begin{array}{l}\text { SOC at arrival } \\
\text { time }\end{array}$ & - \\
\hline$S O C^{D E}$ & $\mathrm{kWh}$ & $\begin{array}{l}\text { SOC at departure } \\
\text { time }\end{array}$ & $S O C^{D E}$ is set by the prosumer. \\
\hline
\end{tabular}

$\theta_{j, i, t+1}^{U}=\beta_{i} \Theta_{j, i, t}^{U}+\left(1-\beta_{i}\right)\left(\theta_{j, t}^{o}+\operatorname{COP}_{i} \cdot R_{i} \cdot\left(P_{j, i, t}^{T C L}+U_{j, i, t}^{T C L}\right)\right)$

$$
+\vartheta_{j, i, t}, \quad \forall j \in J, i \in I^{T C L}, t \in T
$$

$\underline{\theta}_{i} \leq \theta_{j, i, t+1}^{U} \leq \bar{\theta}_{i}, \quad \forall j \in J, \quad i \in I^{T C L}, \quad t \in O_{j, i}$

$\underline{\theta}_{i} \leq \theta_{j, i, t+1}^{D} \leq \bar{\theta}_{i}$

$\forall j \in J, \quad i \in I^{T C L}, \quad t \in O_{j, i}$

The TCL parameters can be variable or fixed. The variable parameters assume the form of scenarios $\left\{\vartheta_{j, i}, \theta_{j}^{o}, O_{j, i}, \forall j, i\right\}$ and are computed on a daily basis. The variable and fixed parameters are described in Tables 4 and 5.

\subsection{Inflexible load}

The inflexible load is modeled through a set of scenarios of power consumption $\left\{\operatorname{Pr}_{j, i}^{I L}, \forall j, i\right\}$. The inflexible load is given by $P_{j, i, t}^{I L}=\operatorname{Pr}_{j, i, t}^{I L}$.

\section{Case study}

The aggregator of prosumers participates in the DA energy and secondary reserve markets of MIBEL during the first week of December 2015 (from November 30th to December 6th). The portfolio of the aggregator includes 1000 prosumers from Porto (Portugal), each one with $1 \mathrm{PV}$ system, $1 \mathrm{TCL}$, and $1 \mathrm{EV}$.

\subsection{Definition of the number of scenarios}

The number of scenarios was set by a two-step heuristic. First, the bidding optimization problems were solved for a number of scenarios from 5 to 50 . Second, the number of scenarios was selected based on the mean absolute error (MAE) and computation time. The MAE measures the differences between the bids computed considering $[5, \ldots, 45]$ scenarios and 50 scenarios. The increase in the number of scenarios, after 25, does not improve significantly the MAE, as shown in Fig. 5. Beyond this value, the increase in computation time does not justify the improvement in uncertainty approximation through a larger set of scenarios. Therefore, the number of scenarios was set to 25 . The computation time for 25 scenarios satisfies the market timeline of MIBEL.

\subsection{Prosumers information}

Four types of prosumers information are considered: TCL

Table 2

\begin{tabular}{|c|c|c|c|}
\hline Symbol & Unit & Name & Description \\
\hline$\eta$ & - & Charging and discharging efficiency & The fixed parameters are provided by the manufacturing companies \\
\hline $\bar{P}^{E V}$ & $\mathrm{~kW}$ & Charging and discharging power rate & \\
\hline$\underline{S O C}$ & $\mathrm{kWh}$ & Minimum state-of-charge & \\
\hline$\overline{S O C}$ & $\mathrm{kWh}$ & Maximum state-of-charge & \\
\hline
\end{tabular}

Fixed parameters of the electric vehicle. 
Table 4

Variable parameters and sets of the thermostatically controlled load.

\begin{tabular}{|c|c|c|c|}
\hline Symbol & Unit & Name & Description \\
\hline$\theta^{O}$ & ${ }^{\circ} \mathrm{C}$ & Outdoor temperature & The aggregator signs a contract with a weather service provider to acquire forecasts/scenarios of outdoor temperatures \\
\hline$O$ & - & House occupancy & $\begin{array}{l}\text { The HEMS is capable of detecting the occupancy of the room through sensors. The HEMS communicates this information and the } \\
\text { aggregator computes scenarios through a seasonal naïve forecasting algorithm }\end{array}$ \\
\hline$\vartheta$ & ${ }^{\circ} \mathrm{C}$ & Heat gains and losses & $\begin{array}{l}\text { The heat gains and losses result from human activity, solar radiation and other loads. They can be estimated by the aggregator using } \\
\text { algorithms based on least squares optimization [31] }\end{array}$ \\
\hline
\end{tabular}

parameters; EV parameters; inflexible load; and PV generation.

\subsubsection{Parameters of the thermostatically controlled loads}

The TCL parameters can be fixed or variable. The fixed parameters are the physical characteristics of the room, technical characteristics of the TCL and thermal comfort of the prosumers. The variable parameters assume the form of scenarios and include outdoor temperature, house occupancy, heat gains and losses.

The parameters of the TCL are the coefficient of performance $C O P$ and the maximum electric power $\bar{P}$. Table 6 presents the parameters of 8 split inverter heat pumps [3].

The physical characteristics of the rooms are the thermal resistance $R$ and the thermal capacitance $C$. Fig. 6 shows the distribution of the rooms' characteristics of the 1000 prosumers (each TCL heats one room). The thermal resistance and capacitance of the rooms were computed based on the physical characteristics of Portuguese buildings.

The scenarios of outdoor temperature were computed by a Gaussian copula method [33] using numerical weather predictions collected from the MeteoGalicia website [34]. Fig. 7 shows twenty-five scenarios of outdoor temperature.

The scenarios of house occupancy were computed by a seasonal naïve forecasting algorithm. Fig. 8 shows twenty-five scenarios of house occupancy.

The scenarios of heat gains and losses were generated by the following Gaussian white noise process: $\vartheta \sim N\left(0,1 \cdot 10^{-6}\right)^{\circ} \mathrm{Cs}^{-1 / 2}$.

The thermal comfort of each prosumer $[\underline{\theta}, \bar{\theta}]$ was selected by choosing one of the following ranges: [19,24]; [20,22]; [20,23]; $[19,22]$.

\subsubsection{Parameters of the electric vehicles}

The EV parameters can be fixed or variable. The fixed parameters are the technical characteristics of the EV. The variable parameters assume the form of scenarios and include plug-in availability, SOCs at departure and arrival times.

The charging and discharging power rate was selected by choosing one of two values: 3.7 or $7 \mathrm{~kW}$ [35]. The battery capacity $\overline{S O C}$ was defined according to a truncated normal distribution [36], described in Table 7.

Figs. 9 and 10 show twenty-five scenarios of $S O C^{A R}, S O C^{D E}$ and availability. The scenarios were computed by a seasonal naïve forecasting algorithm [3]. The availability of the EV is defined by the period between the arrival $t^{D E}$ and departure $t^{A R}$ times $T^{E V}=\left[t^{A R}, \cdots, t^{D E}\right]$. The state-of-charge at departure time $S O C^{D E}$ is equal to the battery capacity of the EV.

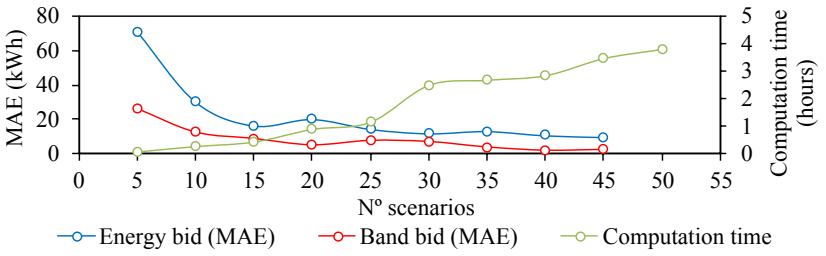

Fig. 5. Computation times and mean absolute errors.

\subsubsection{Inflexible load}

The scenarios of inflexible load $\operatorname{Pr}^{I L}(k W)$ were generated by a Gaussian copula method using load predictions of low-voltage consumers from Portugal for the period of two years (2014-2015). Fig. 11 shows twenty-five scenarios of inflexible load.

\subsubsection{Photovoltaic power generation}

The scenarios of photovoltaic generation $\operatorname{Pr}^{P V}(k W)$ were generated by a Gaussian Copula [33] method using numerical weather predictions collected from the MeteoGalicia website [34]. Fig. 12 shows twenty-five scenarios of PV generation.

\subsection{Electricity market information}

The electricity market information is forecasted by the aggregator and includes energy price $\hat{\lambda}_{t}^{E}(€ / \mathrm{MWh})$, negative imbalance price $\hat{\lambda}_{t}^{\mathrm{E},-}$ (€/MWh), positive imbalance price $\hat{\lambda}_{t}^{\mathrm{E},+}(€ / \mathrm{MWh})$, band price $\hat{\lambda}_{t}^{B}$ $(€ / \mathrm{MW})$, upward tertiary reserve price $\hat{\lambda}_{t}^{U}(€ / \mathrm{MWh})$, downward tertiary reserve price $\hat{\lambda}_{t}^{D}(€ / \mathrm{MWh})$, ratio of upward utilization to band $\widehat{\varnothing}_{t}^{U}$ $(0-1)$, ratio of downward utilization to band $\widehat{\varnothing}_{t}^{D}(0-1)$ and penalty for band not supplied $\hat{\lambda}_{t}^{B,-}(€ / \mathrm{MW})$.

For this case study, the electricity market information was forecasted using the gradient boosting algorithm from the python package "scikit-learn" [37]. One year of data was collected from the ENTSO-E transparency platform [38]. Table 8 presents the performance metrics of the electricity market information. The MAE and root mean square error (RMSE) measure the accuracy of the forecasted market information. The performance of the $\hat{\lambda}_{t}^{E}, \hat{\lambda}_{t}^{B}, \widehat{\varnothing}_{t}^{D}$ and $\widehat{\varnothing}_{t}^{U}$ is good. The remaining prices present a low performance. There is margin for improvement.

The Portuguese TSO sets the penalty for the band not supplied $\lambda_{t}^{B,}$ equal to $1.5 \cdot \lambda_{t}^{B}$ [29]. Fig. 13 shows the forecasted electricity market information for November 30th.

Table 5

Fixed parameters of the thermostatically controlled load.

\begin{tabular}{|c|c|c|c|}
\hline Symbol & Unit & Name & Description \\
\hline$C$ & $\mathrm{kWh} /{ }^{\circ} \mathrm{C}$ & Thermal capacitance & $C$ can be computed by the aggregator using estimation techniques based on least squares optimization [31] \\
\hline$R$ & ${ }^{\circ} \mathrm{C} / \mathrm{kW}$ & Thermal resistance & $R$ can also be computed by estimation techniques, as the thermal capacitance \\
\hline$\beta$ & - & Thermal constant & $\beta=e^{-\frac{\Delta t}{C R}[32]}$ \\
\hline$\underline{\theta} / \bar{\theta}$ & ${ }^{\circ} \mathrm{C}$ & Min. and Max. temperatures of comfort & $\underline{\theta} / \bar{\theta}$ is set by the prosumer and communicated by the HEMS \\
\hline $\mathrm{COP}$ & - & Coefficient of performance & $\mathrm{COP}$ is are provided by the manufacturing company \\
\hline $\bar{P}^{T C L}$ & $k W$ & Maximum electric power & $\bar{P}^{T C L}$ is provided by the manufacturing company \\
\hline
\end{tabular}


Table 6

Parameters of split inverter heat pumps.

\begin{tabular}{|c|c|c|c|c|c|c|c|c|}
\hline Model & 1 & 2 & 3 & 4 & 5 & 6 & 7 & 8 \\
\hline $\mathrm{COP}$ & 3.6 & 3.2 & 3.5 & 3.6 & 4.5 & 3.5 & 4.9 & 4.4 \\
\hline $\bar{P} \quad(\mathrm{~kW})$ & 0.9 & 1 & 1.1 & 1.2 & 1 & 1.5 & 1.1 & 1.5 \\
\hline $\mathrm{A}\left(\mathrm{m}^{2}\right)$ & {$[20,30[$} & {$[20,30[$} & {$[30,40[$} & {$[30,40[$} & {$[40,50[$} & {$[40,50[$} & {$[50,60[$} & {$[50,60[$} \\
\hline
\end{tabular}
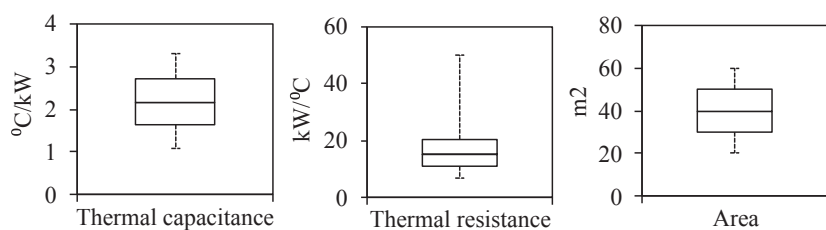

Fig. 6. Physical characteristics of the rooms.

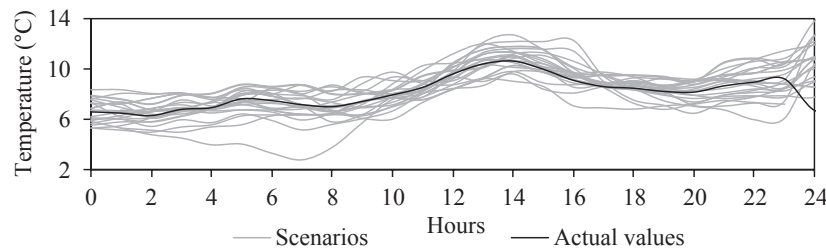

Fig. 7. Twenty-five scenarios of outdoor temperature for November 30th.

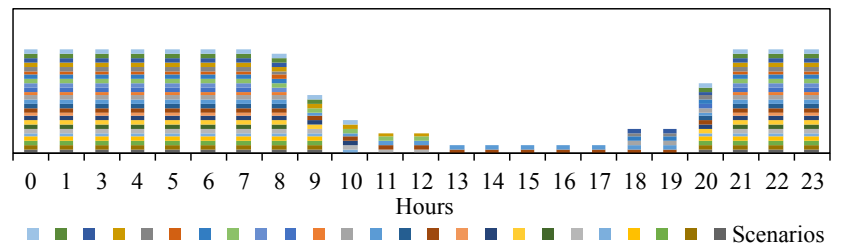

Fig. 8. Twenty-five scenarios of house occupancy for November 30th. A bar means that the household is occupied.

Table 7

Technical parameters of the electric vehicles.

\begin{tabular}{llll}
\hline$\eta$ & $\bar{P}(k W)$ & $\underline{S O C}(\mathrm{kWh})$ & $\overline{S O C}(\mathrm{kWh})$ \\
\hline 0.93 & 3.7 or 7 & $0.1 \cdot \overline{S O C}$ & $\overline{S O C} \sim N(33.3,146.5) 15 \leq \overline{S O C} \leq 70.4$
\end{tabular}

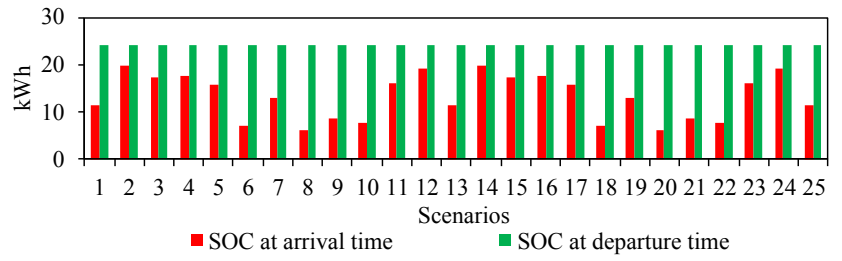

Fig. 9. Twenty-five scenarios of state-of-charge for November 30th.

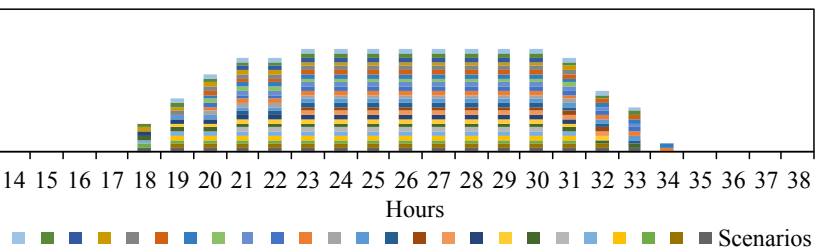

Fig. 10. Twenty-five scenarios of availability for November 30th. A bar means that the electric vehicle is available and plugged-in.

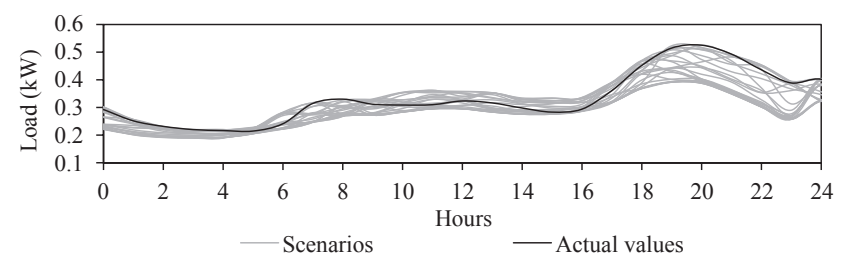

Fig. 11. Twenty-five scenarios of inflexible load for November 30th (one prosumer).

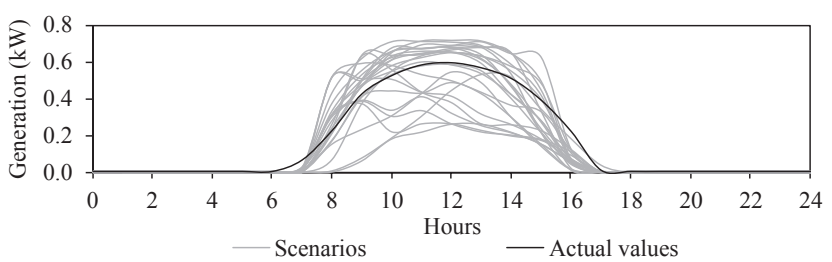

Fig. 12. Twenty-five scenarios of photovoltaic generation for November 30th (system of $1 \mathrm{kWp}$ ).

\section{Results}

The proposed bidding strategy (named dual) is compared to single and inflexible strategies. The single and inflexible strategies consider only the participation of the aggregator in the DA energy market. The single strategy optimizes the aggregator's portfolio, while the inflexible strategy considers that all load and generation are inflexible. Table 9 describes the main characteristics of the three DA bidding strategies. The two-stage stochastic model is described in Section 3.

The results are divided into seven sections. Sections 5.1-5.3 compare the results of three DA bidding strategies. Section 5.4 discusses the remuneration of the prosumers. Section 5.5 discusses the economic value of the prosumers' characteristics. Section 5.6 discusses the contribution of the prosumers' flexibility to the reduction of $\mathrm{CO}_{2}$ emissions. Finally, Section 5.7 describes the computation performance of the bidding approaches.

\subsection{Visual comparison of the day-ahead bidding strategies}

Fig. 14 illustrates the energy and bands bids for November 30th. The energy bids are divided into demand and supply offers. The band bids are divided into upward (2/3) and downward (1/3) directions according to the splitting rule of the MIBEL. The demand and band bids assume positive values and the supply bids assume negative values.

The optimized bidding strategies (dual and single) place most of the demand bids in the hours of low energy prices and the supply bids in the hours of high energy prices (see Fig. 13). The inflexible strategy places most of the demand bids in the hours of high energy prices since no optimization procedure is used. Between the 9th and 14th hours, the aggregator submits bids to the supply side of the energy market, because it corresponds to the time of the day with the highest forecasted PV generation. At night, the supply bids result from EVs operating in V2G mode.

The dual bidding strategy co-optimizes energy and band bids, which empowers the aggregator with four bidding options. Two of the bidding options consist of participating only in the energy market through 
Table 8

Performance metrics of the electricity market information for the first week of December 2015.

\begin{tabular}{|c|c|c|c|c|c|c|c|c|}
\hline & $\hat{\lambda}_{t}^{E}$ & $\hat{\lambda}_{t}^{\mathrm{E},-}$ & $\hat{\lambda}_{t}^{\mathrm{E},+}$ & $\hat{\lambda}_{t}^{B}$ & $\hat{\lambda}_{t}^{U}$ & $\hat{\lambda}_{t}{ }^{D}$ & $\widehat{\varnothing}_{t}^{U}$ & $\widehat{\varnothing}_{t}^{D}$ \\
\hline MAE $(€ / M W h, € / M W$ or $0-1)$ & 2.97 & 8.43 & 7.89 & 1.88 & 16.5 & 8.0 & 0.19 & 0.13 \\
\hline RMSE ( $€ /$ MWh, $€ /$ MW or $0-1$ ) & 3.67 & 10.4 & 9.94 & 2.19 & 26.6 & 11.8 & 0.23 & 0.18 \\
\hline
\end{tabular}
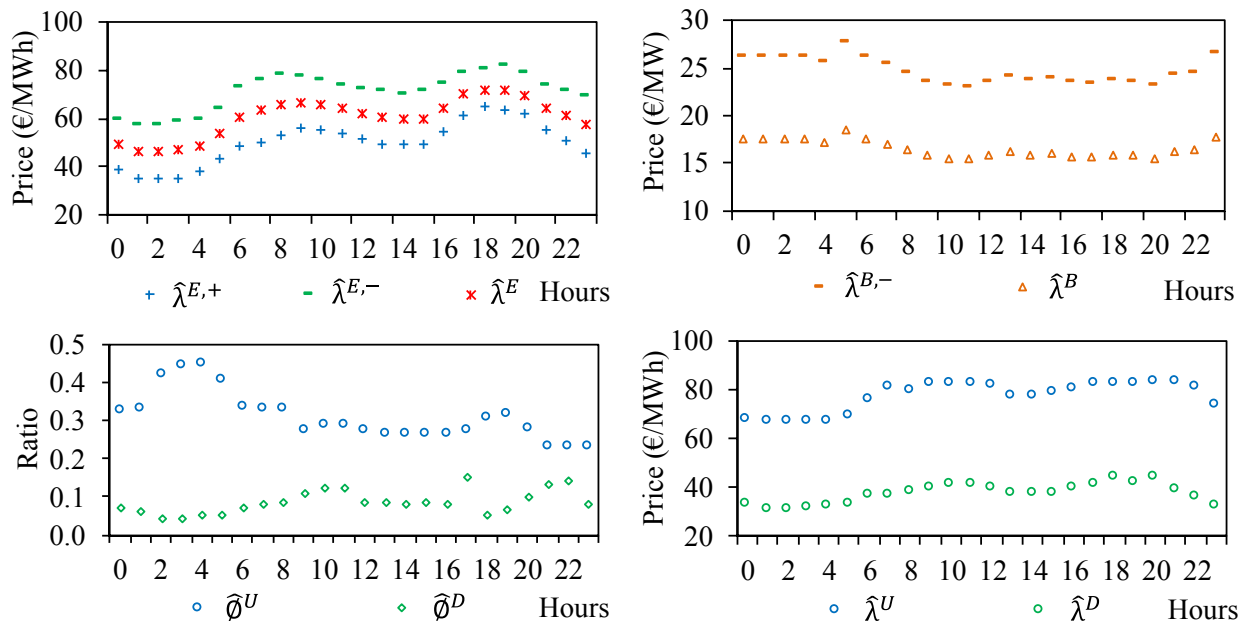

Fig. 13. Forecasted electricity market information for November 30th.

Table 9

Main characteristics of the three day-ahead bidding strategies.

\begin{tabular}{|c|c|c|c|c|}
\hline Strategy & Markets & Optimization model & Prosumers information & Electricity market information \\
\hline Dual & Energy and secondary reserve & Two-stage stochastic & Scenarios & Point forecasts \\
\hline Single & Energy & Two-stage stochastic & Scenarios & Point forecasts \\
\hline Inflexible & Energy & No optimization & Point forecasts & - \\
\hline
\end{tabular}

demand and supply bids. Examples of these two energy bidding options are the 0th and 20th hours. The other two bidding options consist of coupling energy bids with band bids. Examples of these two bidding options are the 4th and 18th hours. The aggregator submits band bids to the DA secondary reserve market when the prosumers have upward and downward flexibilities to offer. The band bids tend to be placed in the hours of high band prices $\hat{\lambda}^{B}$ and high product between upward tertiary reserve prices and ratios of upward utilization to band $\hat{\lambda}^{U} \widehat{\varnothing}_{t}^{U}$. The 3rd and 4th hours are examples of that bidding behavior with band prices $\hat{\lambda}^{B}$ of 17.6 and 17.2€/MW, and products $\hat{\lambda}^{U} \widehat{\varnothing}_{t}^{U}$ of 29.8 and $30.0 € /$ MWh.

\subsection{Comparison of the cumulative bidding results}

Table 10 compares the cumulative bidding energy and power results of the three biddings strategies for the first week of December 2015. The optimized strategies present more supply and demand bids than inflexible strategy since they exploit the prosumers' flexibility (namely V2G) to perform price arbitrage. Under the dual bidding strategy, the aggregator submits high quantities of demand bids to the DA energy market, in order to be able of offering upward band to the DA secondary reserve market. The band bids represent $48 \%$ of the energy bids. This means that the aggregator's portfolio presents a good flexibility range. However, the flexibility is only available in some hours of the day, as described in Fig. 14. In the other hours, selling flexibility in the form of band bids is not cost-efficiency. The results also show that only $26 \%$ of the offered band is expected to be mobilized by the AGC during the RT stage.

Table 11 compares the cumulative financial results of the three biddings strategies for the first week of December 2015. The dual bidding strategy presents the lowest cost of $4.35 \mathrm{k} €$, outperforming single and inflexible strategies with costs of $5.77 \mathrm{k} €$ and $7.18 \mathrm{k} €$. The revenue from selling band contributes to reducing the cost of the aggregator by $1.42 \mathrm{k} €(25 \%)$ and $2.83 \mathrm{k} €(39 \%)$ compared to single and inflexible strategies. The available band and mobilized band present similar monetary values, despite the quantities sold in the market are very different. This is due to the difference of prices between the band and mobilized upward reserve. The annual average prices of upward reserve and band are $81.1 € / \mathrm{MWh}$ and $20.5 € / \mathrm{MW}$, respectively.

\subsection{Disaggregation of the cumulative results}

Table 12 compares the disaggregated load and generation results per type of resource. For the optimized strategies, the EV is the main source of load and generation followed by IL and TCL, as sources of consumption, and PV as a source of generation. For the inflexible strategy, the IL is the main source of consumption followed by EV and TCL. The optimized strategies present higher values of total net load since both consider stochastic scenarios and V2G, unlike inflexible strategy. The inflexible strategy considers point forecasted information in the definition of the energy bids. In addition, the charging and 

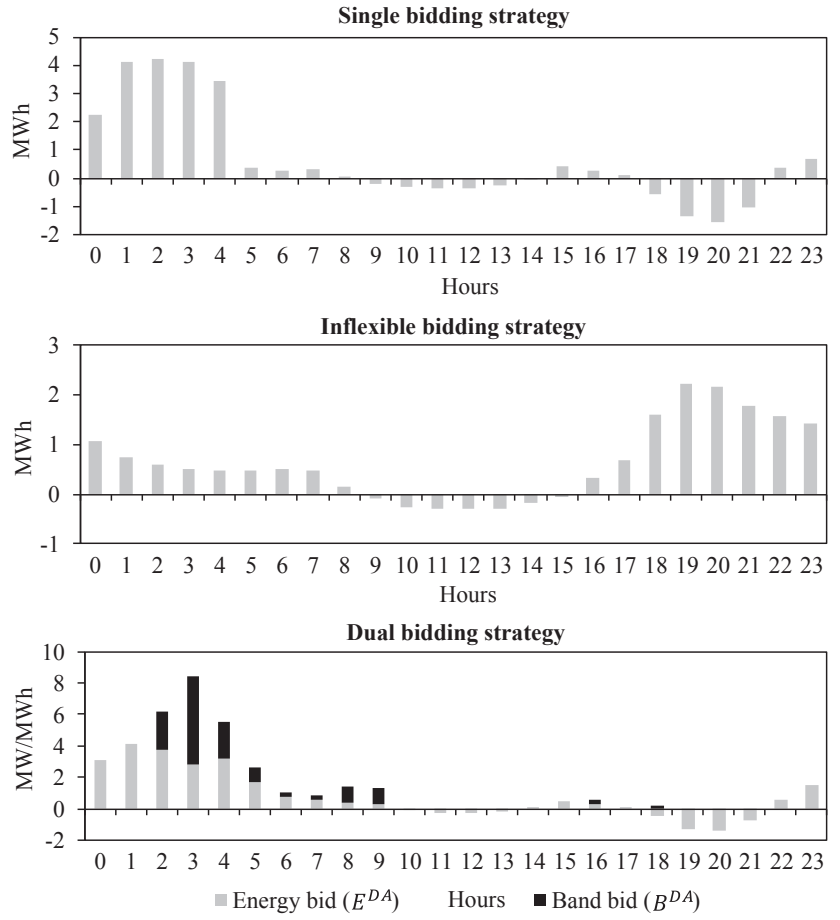

Fig. 14. Energy and band bids for November 30th (Monday). Positive values are demand and band bids and negative values are supply bids.

Table 10

Cumulative energy and power results for one week.

\begin{tabular}{llll}
\hline Bidding strategy & Dual & Single & Inflexible \\
\hline Demand bids $E^{D A}(\mathrm{MWh})$ & 181.7 & 158.7 & 122.4 \\
Supply bids $E^{D A}(\mathrm{MWh})$ & -28.5 & -36.0 & -3.9 \\
Band bids $U^{D A}+D^{D A}(\mathrm{MW})$ & 101.2 & - & - \\
Expected imbalances $\Delta E^{-}-\Delta E^{+}(\mathrm{MWh})$ & 0.1 & -0.02 & - \\
Expected mobilized band $\widehat{\varnothing}^{U} U^{R T}+\widehat{\varnothing}^{D} D^{R T}(\mathrm{MW})$ & 26.0 & - & - \\
Expected band not supplied $\Delta U+\Delta D(\mathrm{MW})$ & 3.8 & - & - \\
\hline
\end{tabular}

Table 11

Cumulative financial bidding results for one week.

\begin{tabular}{llll}
\hline Bidding strategy & Dual & Single & Inflexible \\
\hline Energy cost $(\mathrm{k} €)$ & 9.42 & 8.01 & 7.42 \\
Energy revenue $(\mathrm{k} €)$ & -1.86 & -2.32 & -0.25 \\
Band revenue $(\mathrm{k} €)$ & -1.78 & - & - \\
Expected imbalance cost $(\mathrm{k} €)$ & 0.08 & 0.08 & - \\
Revenue from the expected mobilized band $(\mathrm{k} €)$ & -1.61 & - & - \\
Cost of the expected band not supplied $(\mathrm{k} €)$ & 0.10 & - & - \\
Total net cost $(\mathrm{k} €)$ & 4.35 & $\mathbf{5 . 7 7}$ & $\mathbf{7 . 1 8}$ \\
\hline
\end{tabular}

Table 12

Disaggregation of the load and generation results.

\begin{tabular}{lllllll}
\hline MWh & EV load & EV generation & TCL load & PV generation & IL & Total \\
\hline Dual & 107.9 & -54.5 & 26.8 & -24.2 & 64.8 & 120.8 \\
Single & 117.1 & -62.2 & 27.2 & -24.3 & 64.8 & 122.7 \\
Inflexible & 51.3 & 0.0 & 27.7 & -27.9 & 67.4 & 118.5 \\
\hline
\end{tabular}

discharging cycles of the EVs generate energy losses that increase the expected net load of dual and single strategies.

Table 13 compares the disaggregated upward and downward band results per type of flexible resource. The EV is the main source of
Table 13

Disaggregation of the expected band results.

\begin{tabular}{lcccc}
\hline & EV & TCL & PV & Total \\
\hline Expected upward band (MW) & 46.6 & 13.0 & 5.3 & 64.9 \\
Expected downward band (MW) & 32.3 & $\sim 0$ & $\sim 0$ & 32.3 \\
\hline
\end{tabular}

upward and downward bands followed by the TCL and PV. The EVs are responsible for more than $80 \%$ of the offered band. This justifies the distribution of the band along of the day. Fig. 14 shows that most of the band bids are placed in the early hours of the day, i.e. during the periods of EVs' availability.

\subsection{Remuneration of the prosumers}

Fig. 15 presents the distribution of the weekly aggregator's cost by the prosumers. The results show that the disaggregated costs follow the same trend of the aggregated costs. The dual bidding strategy presents the lowest medium ( $4.2 €$ ) followed by single (5.7€), and inflexible strategies $(7.1 €)$.

The aggregator may adopt different engagement and remuneration mechanisms to gather and promote the participation of prosumers in this flexibility service. One of the mechanisms to remunerate the prosumers consists of a discount on the monthly electricity bill. If the inflexible strategy is adopted as baseline, the monthly average discounts are $12.7 €$ and $6.3 €$ with dual and single bidding strategies. These monthly discounts represent average cost reductions of $40 \%$ and $20 \%$. Fig. 16 presents the distribution of the monthly bill discounts. The dual bidding strategy presents the highest discount of $39.5 €$. The results also suggest that dual and single strategies reduce the individual cost of each prosumer. In this paper, we assume that the aggregator distributes the totality of the cost savings by the prosumers, i.e. the prosumers keep all the savings. The aggregator may charge an administrative fee to remunerate its services.

To maximize the participation of prosumers in this flexibility service, the aggregator can add social and environmental rewards to the monetary incentives. Recent studies have suggested that gamified competition is an effective mechanism to engage prosumers in energy efficiency programs, such as demand response [39].

\subsection{Economic value of the prosumers' preferences and characteristics}

The impact of the prosumers parameters in the economic performance of the dual strategy is discussed in this section. The analyzed

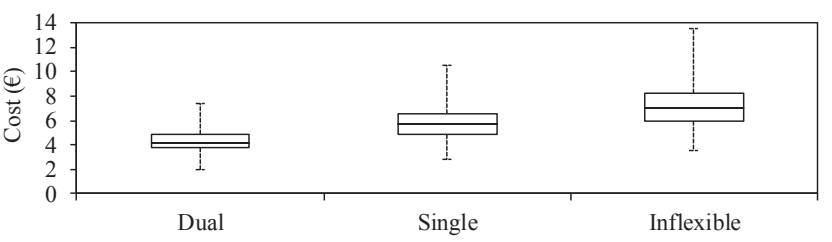

Fig. 15. Distribution of the weekly cost of the aggregator by the prosumers.

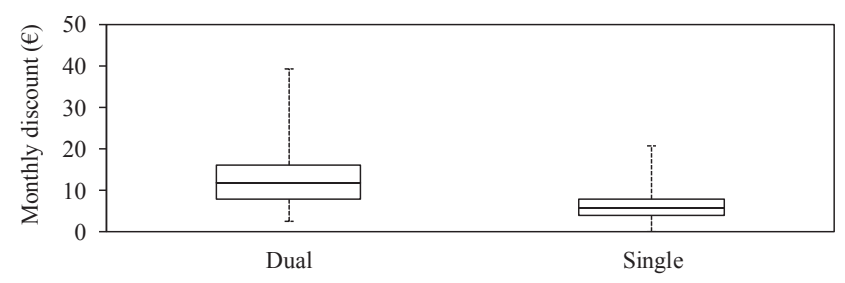

Fig. 16. Distribution of the monthly bill discounts. 
parameters are the following:

1. TCL - length of the temperature range $\bar{\theta}-\underline{\theta}$ and area;

2. EV - length of the availability period $T^{E V}$ and battery capacity $\overline{S O C}$.

The operating cost of the TCL decreases with the increase of the temperature ranges, as described in Table 14. The increase of the temperature ranges in 1 and $2{ }^{\circ} \mathrm{C}$ decreases the monthly operating cost of the TCL in $4 \%$ and $9 \%$. Increasing the temperature range in $1{ }^{\circ} \mathrm{C}$ corresponds to change the preferences of the prosumers from $[20,22]$ to $[22,23]$ or $[19,22]$. On the other hand, increasing the temperature range in $2{ }^{\circ} \mathrm{C}$ corresponds to change the preferences of the prosumers from $[20,22]$ to $[19,23]$.

The margin to reduce electricity costs is higher for bigger houses (or rooms), as described in Fig. 17. The increase of the temperature ranges benefits more houses with larger areas than houses with smaller areas.

The average monthly net cost of an EV is $-0.1 €$ with dual strategy and $14 €$ with inflexible strategy. Under the dual strategy, the EV is a source of revenue instead of being a source of cost. Fig. 18 shows that EVs with large batteries and long periods of availability generate higher values of revenue. In fact, the increase of the availability period changes the economic value of an $\mathrm{EV}$ and transforms it into a source of revenue.

The results presented in this section allow deriving the following business-related conclusions:

1. the preferences of the prosumers significantly affect the cost of the aggregator and prosumers. The aggregator should persuade prosumers to adopt more flexible preferences, such as longer availability periods or larger temperature ranges to reduce costs;

Table 14

Impact of the prosumers' preferences on the monthly cost of the thermostatically controlled loads.

\begin{tabular}{llll}
\hline Temperature range $\left({ }^{\circ} \mathrm{C}\right)$ & {$[20,22]$} & {$[19,22][22,23]$} & {$[19,23]$} \\
Length of the temperature range $\left({ }^{\circ} \mathrm{C}\right)$ & 2 & 3 & 4 \\
Average monthly cost of one TCL $(€)$ & 7.4 & 7.9 & 8.1 \\
\hline
\end{tabular}

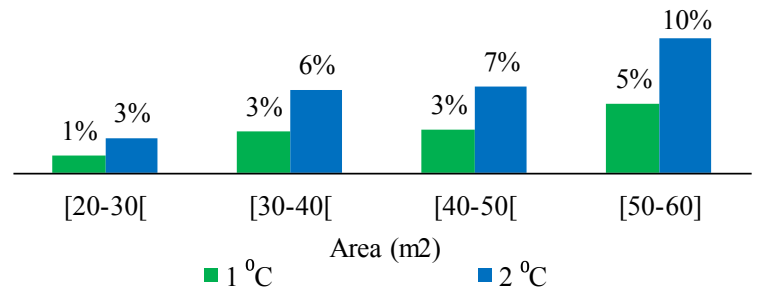

Fig. 17. Monthly savings of the thermostatically controlled loads due to the increase of the temperature ranges in 1 and $2{ }^{\circ} \mathrm{C}$.

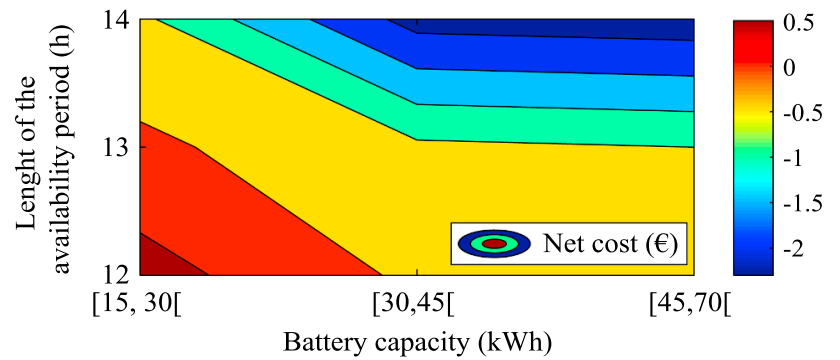

Fig. 18. Impact of the length of the availability period and battery capacity in the monthly net cost of an electric vehicle.
2. houses with larger areas have more margin to reduce electricity costs. It may be easier for the aggregator to attract prosumers with bigger houses;

3. the EV is the main source of flexibility and revenue. Therefore, one of the priorities of the aggregator should pass for attracting EV drivers (preferably EVs with large batteries).

\subsection{Contribution of the prosumers' flexibility to the reduction of $\mathrm{CO}_{2}$ emissions}

The participation of prosumers in flexibility services, such as reserves, can contribute to reducing the use of environmentally unfriendly fossil fuel generators. In Portugal, coal and natural gas combined cycle power stations supplied $163 \mathrm{GWh}$ of secondary reserve in 2015. The provision of this service generated ca. $8.31 \times 10^{7} \mathrm{~kg} \mathrm{CO}_{2}$.

Based on the case study results, a portfolio of 1000 prosumers is capable of supplying $26.0 \mathrm{MWh} /$ week of secondary reserve, which corresponds to $1.35 \mathrm{GWh}$ /year of mobilized secondary reserve. So, the 1000 prosumers may avoid the emission of $6.9 \times 10^{5} \mathrm{~kg} \mathrm{CO}_{2}$ /year, assuming that EVs and TCLs absorb energy generated by renewables. The reduction of $\mathrm{CO}_{2}$ emissions is small, around $0.83 \%$. However, the 1000 prosumers represent a very small percentage of the number of houses in Portugal. Portugal has more than 3 million houses, which is more than enough to reduce the $\mathrm{CO}_{2}$ emissions to zero.

\subsection{Computational performance}

The two-stage stochastic optimization model (1)-(27) was implemented in Python and solved using the linear programming library from the CPLEX 12.7 optimizer on a machine with an Intel@ Xeon ${ }^{\mathrm{TM}} \mathrm{E}$ $5680 \mathrm{CPU}$ clocked at $3.33 \mathrm{GHz}$ and $96 \mathrm{~GB}$ RAM. The execution times and sizes of dual and single bidding optimization models are described in Table 15. The execution times are suitable for the market timeline.

\section{Conclusion}

The expected implementation of smart home technologies promises to turn passive consumers into active and flexible prosumers. The smart home technologies enable the active participation of aggregators of prosumers in the electricity markets. This paper proposes a two-stage stochastic optimization model to support an aggregator of prosumers in the definition of bids for the DA energy and secondary reserve markets. The aim of the aggregator is to minimize the net cost of trading energy and secondary reserve in both DA and RT market stages.

The numerical results show that the proposed bidding strategy (named dual) reduces the cost of both aggregator and prosumers by $40 \%$ and $20 \%$ compared to inflexible and single strategies. The disaggregated results suggest that the prosumers can reduce the monthly electricity bill, on average, by $12.7 €$. Therefore, the dual strategy proves to be an efficient mechanism to transform the prosumers' flexibility into market products with high economic value. Moreover, it contributes to reducing the use of expensive and environmentally unfriendly fuel generators in frequency services.

The main business-related conclusions drawn from the results are the following: the aggregator should persuade the prosumers to be more flexible, e.g. selecting longer availability periods or larger temperature ranges; it may be easier for the aggregator to attract prosumers with

Table 15

Sizes and execution times of the dual and single bidding optimization models (average values).

\begin{tabular}{llll}
\hline & Continuous variables & Constraints & Execution time (min) \\
\hline Dual & $4,666,814$ & $6,618,902$ & 62.8 \\
Single & $2,203,119$ & $1,914,793$ & 3.0 \\
\hline
\end{tabular}


bigger houses; the aggregator should focus primarily on attracting prosumers with EVs since the EV is the main source of flexibility and revenue.

\section{Acknowledgments}

The work of José Iria was supported by Fundação para a Ciência e Tecnologia (FCT) Ph.D. Scholarship PD/BD/113716/2015. This work is also financed by the GREsBAS project (SmartGP/0003/2015) under the framework of ERA-Net Smart Grids Plus.

\section{References}

[1] D'hulst R, Labeeuw W, Beusen B, Claessens S, Deconinck G, Vanthournout K. Demand response flexibility and flexibility potential of residential smart appliances: experiences from large pilot test in Belgium. Appl Energy 2015;155:79-90. https:// doi.org/10.1016/j.apenergy.2015.05.101.

[2] Iria JP, Soares FJ, Matos MA. Trading small prosumers flexibility in the energy and tertiary reserve markets. IEEE Trans Smart Grid 2018. https://doi.org/10.1109/ TSG.2018.2797001. 1-1.

[3] Iria J, Soares F, Matos M. Optimal supply and demand bidding strategy for an aggregator of small prosumers. Appl Energy 2018;213:658-69. https://doi.org/10. 1016/j.apenergy.2017.09.002.

[4] Bessa RJ, Matos MA. Global against divided optimization for the participation of an EV aggregator in the day-ahead electricity market. Part II: numerical analysis. Electr Power Syst Res 2013;95:309-18. https://doi.org/10.1016/j.epsr.2012.08.013.

[5] Bessa RJ, Matos MA. Global against divided optimization for the participation of an EV aggregator in the day-ahead electricity market. Part I: theory. Electr Power Syst Res 2013;95:309-18. https://doi.org/10.1016/j.epsr.2012.08.007.

[6] Vagropoulos SI, Bakirtzis AG. Optimal bidding strategy for electric vehicle aggregators in electricity markets. IEEE Trans Power Syst 2013;28:4031-41. https:// doi.org/10.1109/TPWRS.2013.2274673.

[7] Baringo L, Sánchez Amaro R. A stochastic robust optimization approach for the bidding strategy of an electric vehicle aggregator. Electr Power Syst Res 2017;146:362-70. https://doi.org/10.1016/j.epsr.2017.02.004.

[8] Alahäivälä A, Corbishley J, Ekström J, Jokisalo J, Lehtonen M. A control framework for the utilization of heating load flexibility in a day-ahead market. Electr Power Syst Res 2017;145:44-54. https://doi.org/10.1016/j.epsr.2016.12.019.

[9] Ayón X, Gruber JK, Hayes BP, Usaola J, Prodanović M. An optimal day-ahead load scheduling approach based on the flexibility of aggregate demands. Appl Energy 2017;198:1-11. https://doi.org/10.1016/j.apenergy.2017.04.038.

[10] Iria JP, Soares FJ, Matos MA. Trading small prosumers flexibility in the day-ahead energy market. 2017 IEEE power energy soc gen meet IEEE; 2017. p. 1-5. https:// doi.org/10.1109/PESGM.2017.8274488.

[11] Calvillo CF, Sánchez-Miralles A, Villar J, Martín F. Optimal planning and operation of aggregated distributed energy resources with market participation. Appl Energy 2016;182:340-57. https://doi.org/10.1016/j. apenergy. 2016.08.117.

[12] Perez-Diaz A, Gerding E, McGroarty F. Coordination and payment mechanisms for electric vehicle aggregators. Appl Energy 2018;212:185-95. https://doi.org/10 1016/j.apenergy.2017.12.036.

[13] Mengelkamp E, Gärttner J, Rock K, Kessler S, Orsini L, Weinhardt C. Designing microgrid energy markets. a case study: the Brooklyn microgrid. Appl Energy 2017. https://doi.org/10.1016/j.apenergy.2017.06.054.

[14] Zhang C, Wu J, Zhou Y, Cheng M, Long C. Peer-to-peer energy trading in a microgrid. Appl Energy 2018;220:1-12. https://doi.org/10.1016/j.apenergy.2018.03. 010 .

[15] Bessa RJ, Matos MA. Optimization models for an EV aggregator selling secondary reserve in the electricity market. Electr Power Syst Res 2014;106:36-50. https:// doi.org/10.1016/j.epsr.2013.08.006.

[16] Wang Q, Zhang C, Ding Y, Xydis G, Wang J, Østergaard J. Review of real-time electricity markets for integrating distributed energy resources and demand response. Appl Energy 2015;138:695-706. https://doi.org/10.1016/j.apenergy.2014. 10.048

[17] González P, Villar J, Díaz CA, Campos FA. Joint energy and reserve markets: current implementations and modeling trends. Electr Power Syst Res 2014;109:101-11. https://doi.org/10.1016/j.epsr.2013.12.013.

[18] DeForest N, MacDonald JS, Black DR. Day ahead optimization of an electric vehicle fleet providing ancillary services in the Los Angeles Air Force Base vehicle-to-grid demonstration. Appl Energy 2018;210:987-1001. https://doi.org/10.1016/j. apenergy.2017.07.069.

[19] Peng C, Zou J, Lian L, Li L. An optimal dispatching strategy for V2G aggregator participating in supplementary frequency regulation considering EV driving demand and aggregator's benefits. Appl Energy 2017;190:591-9. https://doi.org/10. 1016/j.apenergy.2016.12.065.

[20] Vrettos E, Oldewurtel F, Andersson G. Robust energy-constrained frequency reserves from aggregations of commercial buildings. IEEE Trans Power Syst 2016;31:4272-85. https://doi.org/10.1109/TPWRS.2015.2511541.

[21] Vrettos E, Andersson G. Scheduling and provision of secondary frequency reserves by aggregations of commercial buildings. IEEE Trans Sustain Energy 2016;7:850-64. https://doi.org/10.1109/TSTE.2015.2497407.

[22] Vrettos E, Kara EC, MacDonald J, Andersson G, Callaway DS. Experimental demonstration of frequency regulation by commercial buildings-Part I: modeling and hierarchical control design. IEEE Trans Smart Grid 2018;9:3213-23. https://doi. org/10.1109/TSG.2016.2628897.

[23] Vrettos E, Kara EC, MacDonald J, Andersson G, Callaway DS. Experimental demonstration of frequency regulation by commercial buildings-Part II: results and performance evaluation. IEEE Trans Smart Grid 2018;9:3224-34. https://doi.org/ 10.1109/TSG.2016.2628893.

[24] Gouveia C, Rua D, Ribeiro F, Miranda L, Rodrigues JM, Moreira CL, et al. Experimental validation of smart distribution grids: development of a microgrid and electric mobility laboratory. Int J Electr Power Energy Syst 2016;78:765-75. https://doi.org/10.1016/j.ijepes.2015.12.005.

[25] Iberian Market Operator (OMIE). Daily and Intraday Electricity Market Operating Rules, Madrid; 2015. < http://www.omie.es/files/20151223_reglas_mercado_ ingles.pdf $>$ [accessed July 5, 2017]

[26] Entidade Reguladora dos Serviços Energéticos (ERSE). Manual of procedures for the management of the power system; 2015 [in Portuguese]. < http://www.erse.pt/pt/ electricidade/regulamentos/operacaodasredes/Documents/MPGGS SE consolidado Abril2014 vsPExterno.pdf > [accessed September 14, 2017]

[27] EPEX, GME, N. Pool, OMIE, OPCOM, OTE, TGE, EUPHEMIA Public Description; 2015. < https://www.nordpoolspot.com/globalassets/download-center/pcr/ euphemia-public-documentation.pdf $>$ [accessed July 5, 2017]

[28] Redes Energéticas Nacionais (REN). Settlement manual for the Portuguese system; 2008. < http://www.mercado.ren.pt/EN/Electr/MarketInfo/Document/ BibSubregula/MPACDezembro2008.pdf >

[29] Adhikari R, Pipattanasomporn M, Rahman S. An algorithm for optimal management of aggregated HVAC power demand using smart thermostats. Appl Energy 2018;217:166-77. https://doi.org/10.1016/j.apenergy.2018.02.085.

[30] Zhou Y, Wang C, Wu J, Wang J, Cheng M, Li G. Optimal scheduling of aggregated thermostatically controlled loads with renewable generation in the intraday electricity market. Appl Energy 2017;188:456-65. https://doi.org/10.1016/j.apenergy. 2016.12.008

[31] Maasoumy M, Sangiovanni-Vincentelli A. Total and peak energy consumption minimization of building HVAC systems using model predictive control. IEEE Des Test Comput 2012;29:26-35. https://doi.org/10.1109/MDT.2012.2200871.

[32] Callaway DS. Tapping the energy storage potential in electric loads to deliver load following and regulation, with application to wind energy. Energy Convers Manage 2009;50:1389-400. https://doi.org/10.1016/j.enconman.2008.12.012.

[33] Pinto R, Bessa RJ, Matos MA. Multi-period flexibility forecast for low voltage prosumers. Energy 2017;141:2251-63. https://doi.org/10.1016/j.energy.2017.11. 142.

[34] Meteogalicia; n.d. < http://www.meteogalicia.gal/web/index.action > [accessed July 26, 2017].

[35] Iria JP, Soares FJ, Franchin IG, Silva N. Development of a novel management system for electric vehicle charging. 2014 IEEE int electr veh conf IEEE; 2014. p. 1-7. https://doi.org/10.1109/IEVC.2014.7056096.

[36] Soares FJ, Lopes JAP, Almeida PMR. A stochastic model to simulate electric vehicles motion and quantify the energy required from the grid. 2011 17th power syst comput conf. 2011. p. 22-6http://www.pscc-central.org/uploads/tx ethpublications/fp359.pdf.

[37] Pedregosa F, Varoquaux G, Gramfort A, Michel V, Thirion B, Grisel O, et al. Scikitlearn: machine learning in Python. J Mach Learn Res 2012;12:2825-30. https://doi. org/10.1007/s13398-014-0173-7.2.

[38] Hirth L, Mühlenpfordt J, Bulkeley M. The ENTSO-E transparency platform - a review of Europe's most ambitious electricity data platform. Appl Energy 2018;225:1054-67. https://doi.org/10.1016/j.apenergy.2018.04.048.

[39] Barbosa A, Iria J, Cassola F, Coelho A, Portela J, Küçük Ü, Madureira AG, Zehir MA Ozdemir A, Soares FJ. GReSBAS project: a gamified approach to promote more energy efficient behaviours in buildings. Electr electron eng (ELECO), 2017 10th int conf, Bursa, Turkey. 2017. p. 1258-61http://ieeexplore.ieee.org/stamp/stamp.jsp? $\mathrm{tp}=$ \&arnumber $=8266391$. 